\title{
Charge the community but delay its care
}

\author{
If the delay allows time for thought, good - but it probably won't
}

Plans that would have enabled vulnerable elderly and disabled people to stay in their own homes were postponed by the government last week ( $\mathrm{p} 142$ ). ${ }^{1}$ The poll tax has been a greater burden than expected for local authorities and the public (and a greater vote loser, perhaps). The additional increase needed to pay for community care would be unfair, said Mr Kenneth Clarke, the Secretary of State for Health. Though he blamed local authorities for failing to balance their books, he acknowledged that they would need more time to come to terms with the substantial new responsibility of running community care. This revelation should have been no surprise to the government, given that it is responsible for the administrative hurdles of the poll tax, the new Children Act, and changes to education that face local authorities in the coming year.

The reforms would have redirected social security money to local authorities so that they could assess people's needs for care and appoint case managers to arrange and buy it. For elderly and physically handicapped people this could have meant living at home, with more domiciliary help and more access to day centres. Now they must wait, and so must their families and friends whose unpaid support saves the treasury an estimated $£ 20$ billion a year. Money already spent on implementing the reforms by local authorities, voluntary groups, and private firms may have been wasted. Will hospitals be able to reverse plans to close geriatric beds?

For people with psychiatric problems, whose plight has received more attention, there is better news. A specific grant will be paid to local authorities for the social care of severely mentally ill people. But less than two thirds of the promised $£ 30 \mathrm{~m}$ will be paid, and local authorities will have to find $£ 9 \mathrm{~m}$ next year. Although the grant is a step in the right direction (and is probably all that Mr Clarke can get from the Treasury in its fight against inflation), it is not nearly enough. It will spread very thinly among the 550000 severely mentally ill people who are said to need it, and will pay for the care of only 3000 people with schizophrenia, according to the National Schizophrenia Fellowship. ${ }^{2}$ An additional $£ 2 \mathrm{~m}$ for those on the streets, recently announced, is another ray of hope but will take up to three years to appear.

The community care proposals were the most welcome part of the government's health reforms. They were by no means perfect: fears were expressed about the hurried time table, the lack of information on existing needs and services, the bureaucratic overload, and, most importantly, the failure to "ring fence" most of the money that local authorities would receive. But coordination of social care was an improvement on the current arrangements. If the next three years are spent constructively, reviewing these deficiencies, then the delay may be a godsend. But if there are other reasons for the delay more pressing priorities might occupy the government's time and the most vulnerable people in our society may suffer.

TRISH GROVES

Assistant editor, $B M \mathcal{F}$

1 Warden J. Community care unreformed. Br Med f 1990;301:198

2 Sherman J, Young D. $£ 30 \mathrm{~m}$ grant for mentally ill is "drop in ocean." The Times 1990 July 19:2

\section{Regular Review}

\section{Colles' fracture}

\section{Failure in management may cause permanent disability}

The most common type of wrist fracture was first described by Abraham Colles in 1814; it is at the distal radius and typically the lower radial fragment is dorsally and laterally angulated together with rotational deformity in supination. ${ }^{1}$ There is concomitant damage to the inner aspect of the wrist, either stretching or rupture of the ulnar collateral ligament or fracture of the ulnar styloid, this often remaining ununited.

The usual victim is a middle aged or elderly woman who falls on the outstretched palm of her hand, force being translated upwards to the glenohumeral articulation of the shoulder. Classically, there is a "dinner fork" deformity of the wrist with painfully limited movement of the wrist joint and of rotation of the forearm.

Other fractures that occur at the wrist joint are those at the radial styloid, Smith's fracture with the opposite deformity of a Colles' fracture, the unstable marginal fractures of the radius described by Barton, and lunate facet "die punch" injuries from impaction of the lunate into the radius..$^{2-4}$ Injuries that need to be considered in the differential diagnosis of Colles' fracture also include isolated damage to the inferior radioulnar joint and fractures of the scaphoid, which are common in young men.

The frequency of Colles' fractures in women increases sixfold between the ages of 35-39 and 60-64 and then levels off. The incidence is lower in men, with a less dramatic rise in the more elderly. ${ }^{5}$ Epidemics of fractures occur in periods of snow and ice, resulting in considerable demand on accident and emergency departments. Both men and women with osteoporosis tend to have greater deformity after Colles' fractures than do those with normal bone texture, and there seems to be some correlation between deformity and bone quality. ${ }^{6}$

\section{Immediate management}

The patient with a Colles' fracture requires radiographs to confirm the diagnosis, and the displaced fracture then requires reduction; this may be performed under general anaesthesia, axillary or interscalene brachial block, intravenous regional anaesthesia (this is not always without risk), or, most conveniently, a haematoma block..$^{7-10}$ The patient is placed supine and, after preparation of the skin, $5 \mathrm{ml}$ of $2 \%$ plain lignocaine is injected dorsally into the fresh haematoma; in the patient with acute injury this usually provides perfectly adequate anaesthesia in five minutes (fig 1 ).

With countertraction on the arm above the elbow, the hand 
is pulled to disimpact the fracture; after this, it is best to use the method of Robert Jones to correct fully the deformity of the lower radius. " The thenar eminence of one hand of the manipulator is placed dorsally over the lower radius at the wrist and the other hand placed on the lower forearm in line with the radial shaft: the lower radial fragment is then manipulated in a volar and medial direction and is also pronated to overcome the supination deformity (fig 2).

A reduced Colles' fracture cannot certainly be held in good position by a forearm plaster of Paris splint or cast alone: rotation of the forearm must be prevented in addition to immobilisation of the wrist to minimise risk of redisplacement of the lower radial fragment. In the elderly (most of the patients) it is unwise to rigidly immobilise the elbow-as the joint readily becomes stiff-when function of the arm is further considerably impaired. The ideal may be a hinged brace extending above the elbow, but this may be expensive and difficult when many patients have to be treated in an accident and emergency department. An excellent compromise is the "sugar tong" plaster splint applied over padding ${ }^{12}$; for most patients the splint should be 7.5 or $10 \mathrm{~cm}$ wide and extend dorsally from the metacarpophalangeal joints of the fingers and then around the elbow and back along the volar surface of the forearm to the palm of the hand, allowing proper function of the fingers and thumb (fig 3). The splint is bandaged in position with the forearm in full pronation, with no more than $20^{\circ}$ of palmar flexion of the wrist and some ulnar deviation. Check that the radiographs show the lower radial fragment well reduced with normal palmar tilt to the lower radial articular surface; ideally there should be normal radial inclination and length in the anteroposterior view.

Sarmiento et al have argued that it may be best to immobilise the forearm in full supination with palmar flexion at the wrist. ${ }^{13}$ This requires an above elbow cast to keep the elbow rigidly immobilised and release the deforming pull of the brachioradialis muscle; the concept has not gained general

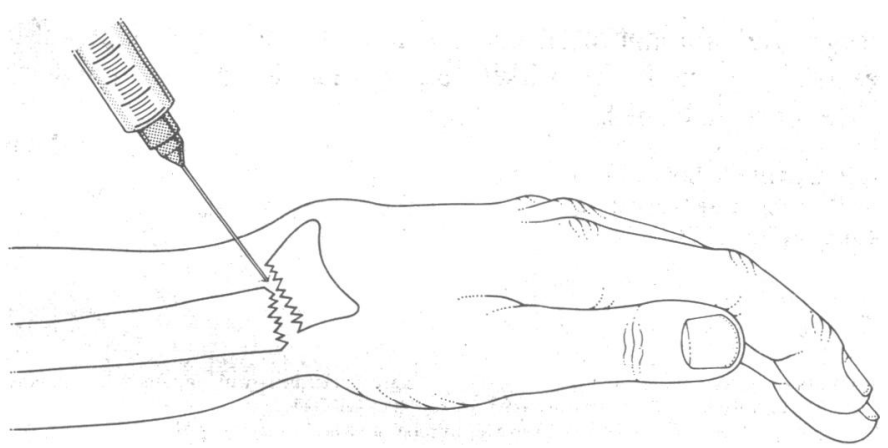

FIG 1-In most cases the simplest and best anaesthetic is a haematoma block, which is produced by lignocaine

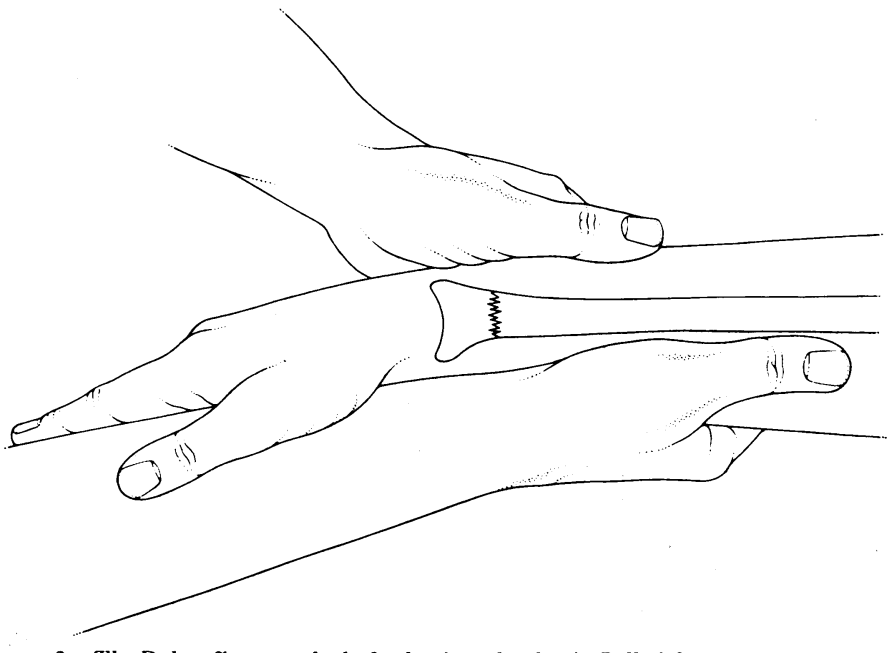

FIG 2-The Robert Fones method of reduction of a classic Colles' fracture

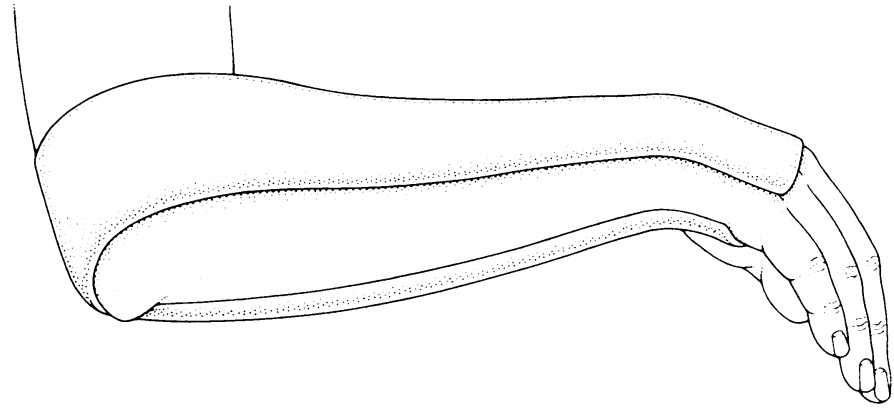

FIG 3-After reduction the fracture should be immobilised for at least three weeks in a well padded sugar tong splint and thereafter in a forearm cast for two weeks

acceptance, and there must be risk in middle aged and elderly people of permanent stiffening of the elbow, wrist, and fingers as a consequence of this type of immobilisation. ${ }^{1+}$

The usual warnings about impaired circulation should be given to the patient, who should also be advised actively to move the shoulder and the elbow as well as the fingers and thumb to limit the risk of post-traumatic stiffness.

\section{Redisplacement}

A Colles' fracture may easily become redisplaced within a week after reduction of the swelling. The usual and essential practice is to take check radiographs a week to 10 days after the injury; if redisplacement has occurred then further manipulation will certainly be required in patients with good bone texture, remanipulation being generally more successful in those under $60 .{ }^{15}$ In some cases it may be wise to check with further radiographs two weeks after injury; later than this it is usually not possible to correct the position of the lower radial fragment by closed manipulation. The "sugar tong" splint should remain in position for three weeks, then a forearm cast may be used for the remaining two weeks of immobilisation.

After the period of immobilisation physiotherapy helps to encourage active motion of the wrist and forearm, and this can be usefully supplemented by wax baths. Exercises should not be too vigorous in the beginning, however, or post-traumatic flexor synovitis within the carpal tunnel may be aggravated, with an increased risk of median compression neuropathy. ${ }^{16}$

Particularly unstable comminuted Colles' fractures may require other methods of immobilisation: external fixation, a special buttress plate and screws (the screws engaging both the lower shaft and the radial fragment), intramedullary stabilisation with methylmethacrylate cement, or, more simply, percutaneous pin fixation..$^{17-20}$

\section{Complications}

The complications of Colles' fractures include malunion with unsightly deformity, persisting translation of the carpus with the lower radial fragment, shortening of the radius, dissociation of the inferior radioulnar joint with prominence dorsally of the head of the ulna, stiffness of the wrist and forearm, and stiffness, even freezing, of the shoulder. There are other, less common, potential complications: carpal tunnel syndrome, Sudeck's atrophy, ulnar and radial compression neuropathy, rupture of the extensor pollicis longus tendon, entrapment or rupture of the deep flexor tendons to the fingers, interosseous membrane contracture, midcarpal instability, and, very rarely, non-union. ${ }^{1621-26}$ If the articular surface of the radiocarpal articulation of the wrist joint has been damaged then the stage is set for progressive osteoarthritic change in later life.

Far too many patients with displaced Colles' fractures end up with very unsightly deformity of the wrist - often a cause of continuing concern. Useful function may often still be 
obtained, but the wrist is working at a mechanical disadvantage: function of the hand and wrist has been shown to be related not only to the severity of the initial displacement of the fracture but also to the anatomical result. ${ }^{27-9}$ Certainly, successful reduction and its maintenance until bony union are important for function of the hand, wrist, and arm. When malunion does occur surgical corrective measures are probably best restricted to younger patients with not less than $70 \%$ of the normal range of wrist motion; there should be no degenerative osteoarthritic changes at the radiocarpal joint and bone texture should be good. Reconstructive surgery usually consists of an open wedge osteotomy of the lower radius, the gap being filled with bone graft; it is always wise to fix the osteotomy internally. ${ }^{30}$

Some patients complain of persisting limitation of forearm rotation, perhaps accompanied by pain. This may sometimes be dealt with by surgery to the lower ulna; an attractive operation is cuff resection with arthrodesis of the head of the ulna to the radius, a screw being used for fixation, thus providing future stability for the carpus. ${ }^{31}$ Stability of the lower ulna may also be achieved after resection of the ulna head by looping an artificial ligament from the radius to the ulna (J M Hunter, personal communication).

Persisting carpal tunnel syndrome is an uncommon complication of Colles' fracture, but it is more likely to occur if the wrist is palmar flexed more than $20^{\circ}$ in a splint or cast, the volume of the carpal tunnel being significantly less beyond this degree of angulation. ${ }^{32}$ In a few patients the palsy is transient and requires no treatment, and in others conservative measures are successful: a night splint, non-steroidal antiinflammatory drugs, and injection of steroid and local anaesthetic into the carpal tunnel. Other patients require surgical decompression, especially if there is thenar wasting and weakness of opposition of the thumb; very occasionally opponensplasty is required.

The unusual complication of reflex sympathetic dystrophy (Sudeck's atrophy) may be more likely to occur when palmar flexion of the wrist has been beyond $20^{\circ}$ during the period of immobilisation; this may be a very difficult problem to treat. The patient complains of particularly bothersome pain, swelling of the soft tissues in the beginning, and exquisite tenderness with circulatory changes in the skin, which may appear purple and cold; excess perspiration may also occur.
Eventually tapering deformity of the fingers may develop with extreme stiffness of the fingers and thumb and wrist and, in some, the forearm, elbow and shoulder; radiographs show mottled decalcification and osteoporosis.

Reasonable return of function may be obtained in many of these unfortunate patients by active and passive exercises conducted with the help of a physiotherapist and occupational therapist. Guanethidine sympathetic blocks may be useful, as may be a short course of treatment with prednisolone $5 \mathrm{mg}$ three times a day over six weeks; small doses of diazepam may also help. It is often best to admit the patient to hospital for such treatment and for the arm to be kept elevated; fitting spring braces to the fingers to attempt to undo flexion deformity of the proximal interphalangeal joints may also be useful.

Rupture of the extensor pollicis longus tendon may occur weeks or even months after union of the Colles' fracture. This is a disabling injury as the thumb is laid across the palm and cannot be taken out to grip objects. This is an attrition rupture of the tendon at Lister's tubercle of the lower radius. It is impossible to perform a direct anastomosis, but there are several surgical options: transfer of the extensor indicis into the distal segment of the ruptured tendon, intercalated tendon graft, or transfer of the extensor carpiradialis longus tendon from its insertion at the index metacarpal into the ruptured distal end of the tendon, which is a simple and effective technique requiring only one surgical incision. ${ }^{33-35}$

In summary, important pitfalls in the management of Colles' fractures are imperfect reduction and immobilisation; lack of check radiographs at seven to 10 days for the position of the fracture; confusion with other unstable injuries of the lower radius, in particular Barton's fracture; palmar flexion beyond $20^{\circ}$ in a splint or cast; and lack of advice to the patient about active movement of the fingers and thumb, the elbow, and the shoulder. There is certainly room for improvement in managing this common injury, the end result so often being a source of disappointment and concern to the patient; but even its proper management cannot always lead to an acceptable result, especially in middle aged and elderly women with osteoporotic bones.

Consultant Orthopaedic Surgeon,

THOMAS G WADSWORTH

St Bartholomew's Hospital

London EC1A 7BE
1 Colles A. On the fracture of the carpal extremity of the radius. Edinburgh Medical and Surgical foumal 1814;10:182-6.

Smith RW. A treatise on fractures in the vicinity of $j$
dislocations. Dublin: Hodges and Smith, 1847. arton JR. Views anc
$1838: 1: 365-8$.

4 Axelrod T, Paley D, Green J, McMurtry RY. Limited open reduction of the lunate facet in comminuted intra-articular fractures of the distal radius. F Hand $S$ urg $[\mathrm{Am}]$ 1988;13:372-7.

5 Owen RA, Melton LJ, Johnson KA, Ilstrup DM, Riggs BL. Incidence of Colles' fracture in a North American community. Am F Public Health 1982;72:605-7

6 Dias JJ, Wray CC, Jones JM. Osteoporosis and Colles' fractures in the elderly. 7 Hand Surg [Br] 1987;12:57-9

7 Bier A. Über einen neuen Weg local Anaesthesia an der Gliedmassen zu erzeugen. Archiv für Klinische Chirurgie 1908;86:1007-16.

8 Heath ML. Deaths after intravenous regional anaesthesia. Br.Med $\mathcal{f}$ 1982;285:913-4.

9 Cobb $\mathrm{AG}$, Houghton GR. Local anaesthetic infiltration versus Bier's block for Colles' fractures. Br.Med f 1985;291:1683-4.

10 Case RD. Haematoma block-a safe method of reducing Colles' fractures. Injury 1985;16:469-70. 11 Baldwin WI. Orthopaedic surgery of the hand and wrist. In: Jones R, ed. Orthopaedic surgery of injuries by various authors. Vol 1. London: Oxford University Press, 1921:241-82.

12 Howes DS, Kaufman JJ. Plaster splints: techniques and indications. American Fumily Physician 1984:30:215-21.

13 Sarmiento A, Pratt GW, Berry NC, Sinclair WF. Colles' fracture. Functional bracing in supination. F Bone foint Surg [Am] 1975;57:311-7.
surmitis

14 Wilson C, Venner RM. Colles' fracture, immobilisation in pronation or supination? $\mathcal{I} R$ Coll Surg Edinb 1984;29:109-11.

15 McQueen MM, MacLaren A, Chalmers J. The value of remanipulating Colles' fractures. I Bone foint Surg [Br] 1986;68:232-3.

16 Nagendran K, MacLean JGB. Electrophysiology of median nerve lesions following Colles' fracture. A retrospective study. Electroencephalogr Clin Neurophysiol (in press

17 Cooney WP, Linscheid RL, Dobyns JH. External pin fixation for unstable Colles' fractures. I Bone foint Surg [Am] 1979;61:840-5.

18 Müller ME, Allgöwer M, Schneider R, Willeneger $\mathrm{H}$, eds. The A0 buttress plate for fracture of the distal radius. In Manual of internal fixation. Berlin: Springer-Verlag, 1979:196-7.
19 Kofoed H. Comminuted displaced Colles' fractures, treatment with intramedullary methylmethacrylate stabilisation. Acta Orthop Scand 1983;54:307-11.

20 Clancey GJ. Percutaneous Kirschner-wire fixation of Colles' fractures. 7 Bone foint Surg (Am].

1984;66:1008-14. fracture. Clin Orthop 1988;233:217-25.

22 Sudeck PMH. Ueber die acute entzündliche Knockenatrothie. Archiv für Klinische Chirurgie $1900 ; 62: 147-56$.

23 Smith FM. Late rupture of extensor pollicis longus tendon following Colles' fracture. 7 Bone foint Surg $[\mathrm{Am}]$ 1946;28:49-59.

24 Stuart MJ, Beckenbaugh RD. Flexor digitorum profundus entrapment after closed treatment of a displaced Colles' fracture. F Hand Surg (Am) 1987;12:413-5.

25 Diamond JP, Newman JH. Multiple flexor tendon ruptures following Colles' fracture: a case report. $\mathcal{F}$ Hand Surg $[\mathrm{Br}]$ 1987;12:112-4.

26 Taleisnik J, Watson HK. Midcarpal instability caused by malunited fractures of the distal radius. f Hand Surg [Am] 1984;9:350-7

27 Altissimi M, Antenucci R, Fiacca C, Mancini C. Long-term results of conservative treatment of fractures of the distal radius. Clin Orthop 1986;206:202-10.

28 Jenkins NH, Mintowt-C $z y z$ WJ. Mal-union and dysfunction in Colles' fracture. $f$ Hand Surg $/ \mathrm{Br}$ 1988;13:291-3.

29 McQueen M, Caspers J. Celles' fracture: Does the anatomical result affect the final function? f Bone foint Surg/Br] 1988;70:649-51.

30 Fernande DL Correction of post-trat atic wrist deformity in aduls by osteotomy hone-grafting and internal fixation. F Bone foint Surg [Am] 1982;64:1164-78.

31 Sauvé, Kapandii. Nouvelle technique de traitement chirurgical des luxations récidivantes isolées de l'extrémité inferieure du cubitus. F Surg 1936;47:589-94.

32 Gelberman RH, Szabo RM, Mortensen WW. Carpal tunnel pressures and wrist position in patient with Colles' fractures. $\mathcal{F}$ Trauma 1984:24:747-9.

33 Browne EZ, Teague MA, Snyder CC. Prevention of extensor lag after indicis proprius tendon transfer. F Hand Surg [Am] 1979;4:168-72.

34 Hamlin C, Littler JW. Restoration of the extensor pollicis longus tendon by an intercalated graft. f Bone foint Surg [Am] 1977;59:412-4.

35 Wadsworth TG. Extensor carpi radialis longus transfer for rupture of the extensor pollicis longus tendon. In: Boswick JA Jr, ed. Advances in upper extremity surgery and rehabilitation. Rockville, Maryland: Aspen Publishers, 1986:193-9. 